\title{
PITUITARY CONTENT OF FOLLICLE-STIMULATING HORMONE IN IMMATURE MALE RATS
}

\author{
BARBARA R. PEARGE AND P. S. BROWN \\ Department of Pharmacology, University of Bristol, \\ The Medical School, University Walk, Bristol BS8 1TD
}

(Received 8th August 1969)

Data on the pituitary content of follicle-stimulating hormone (FSH) in immature female rats have been published (Kragt \& Ganong, 1968; Goldman \& Mahesh, 1968; Fawke \& Brown, 1970), but there seems to be little comparable information about the male. The following results have been obtained in males from our colony of Porton rats: the experiments were under conditions similar to those used in a previous investigation of the females (Fawke \& Brown, 1970).

Three series of measurements were made (see Table 1). Results are strictly comparable within each series as they were obtained from animals born on the same day. In Series B and C, rats were randomized individually; in Series A, which involved unweaned rats, whole litters were killed together and only the allocation of litters was random. The animals were killed between 09.00 and

TABLE 1

PITUITARY FSH GONTENT OF MALE RATS OF VARIOUS AGES

\begin{tabular}{c|c|c}
\hline Series & $\begin{array}{c}\text { Age } \\
(\text { days })\end{array}$ & $\begin{array}{c}\text { FSH } \\
(\mu g \text { NIH-FSH-S1 } / \text { gland }) \\
(95 \% \text { fiducial limits })\end{array}$ \\
\hline A & 11 & $18(15$ to 24$)$ \\
& 16 & $43(35$ to 55$)$ \\
B & 21 & $30(24$ to 37$)$ \\
& 22 & $79(43$ to 218$)$ \\
& 24 & $141(74$ to 645$)$ \\
& 26 & $98(58$ to 162$)$ \\
& 28 & $121(73$ to 201$)$ \\
& 30 & $156(97$ to 252$)$ \\
C & 32 & $109(74$ to 166$)$ \\
& 34 & $98(66$ to 149$)$ \\
& 36 & $124(71$ to 203$)$ \\
& 48 & $166(118$ to 236$)$ \\
& 40 & $151(107$ to 205$)$ \\
& 45 & $195(128$ to 337$)$ \\
& 50 & $221(122$ to 341$)$ \\
& 60 & $206(133$ to 862$)$ \\
& 70 & $374(216$ to 821$)$ \\
& & $744(422$ to 1612$)$ \\
\hline
\end{tabular}

Ten donor rats supplied material for each age-group in Series B and C. In Series A, groups of forty, seventeen and twenty-five donor rats were used. 
11.00 hours with chloroform vapour and their anterior pituitaries quickly removed and homogenized in $0.9 \% \mathrm{NaCl}$ solution. The homogenates were stored at $-20^{\circ} \mathrm{C}$ until assayed for Fsh by the method of Steelman \& Pohley (1953) using ovine NIH-FSH-s1 as standard. In all assays, both standard and unknown were used at not less than two dose-levels and gave valid parallel-line assays. Details of the methods and experiments to test their suitability have been

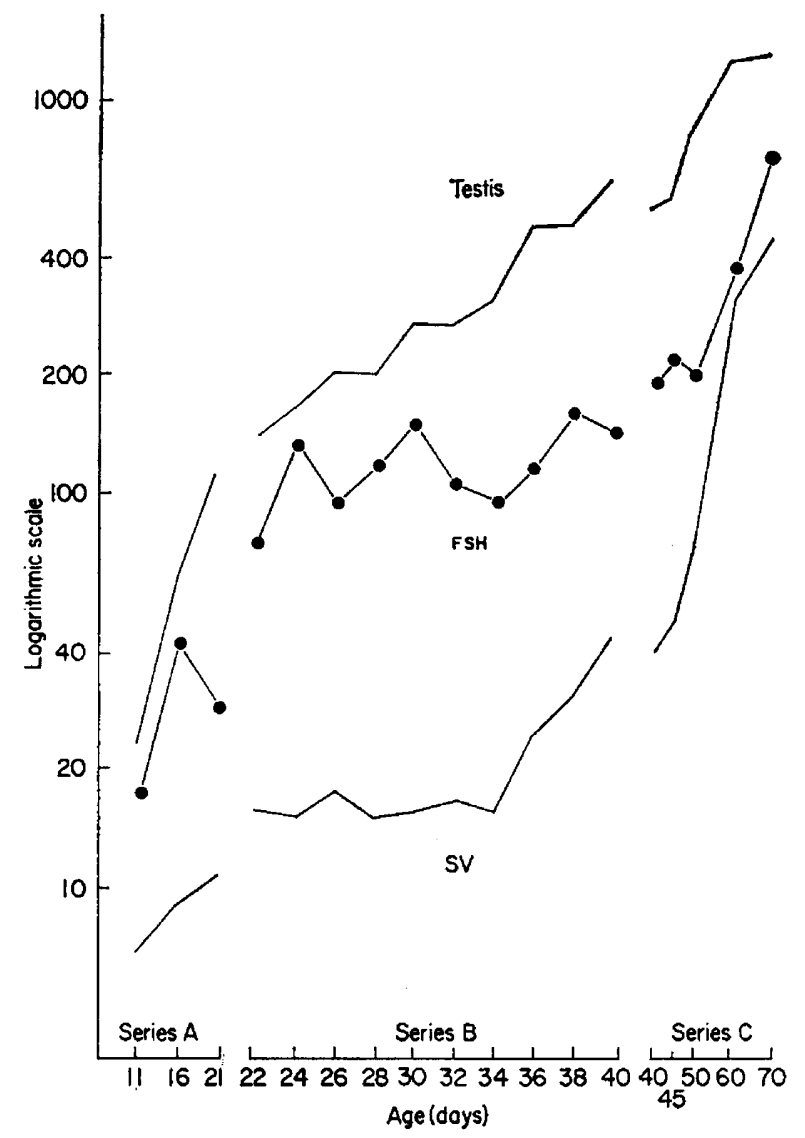

TEXT-HIG. 1. Pituitary FSH ( $\mu$ g NIH-FSH-sl/gland) and mean weights (mg) of seminal vesicles + coagulating gland (SV) and right testis of male rats of different ages all plotted on the same logarithmic scale. $95 \%$ fiducial limits for the rsH estimations are shown in Table 1. Note that age is shown on different scales in the three series.

described previously (Fawke \& Brown, 1970). Body weight was recorded and organs including the seminal vesicles plus coagulating gland and the testes were weighed after fixation. In most cases, the pituitary tissue was not weighed but was homogenized and frozen as rapidly as possible. Pituitary weights were obtained from another series of comparable animals.

FSH was measurable at the age of 11 days (Table 1). Between the ages of 22 days (one day after weaning) and 40 days (Series B), pituitary content varied between 79 and $166 \mu \mathrm{g}$ NIH-FSH-sl/gland. There were fluctuations but these do not appear significant when seen in combination with the errors of the 
assay (Table 1). While total content changed little over this period, the concentration of FSH probably tended to fall slightly as the mean anterior pituitary weight of comparable rats rose from $1.87 \mathrm{mg}$ at 22 days to $4.08 \mathrm{mg}$ at 40 days. Testis weight increased $4 \cdot 5$-fold over this interval (Text-fig. 1), while body weight rose 2-3-fold: it is, therefore, likely that Fst was being secreted. The seminal vesicles did not begin to increase strikingly in weight until after 34 days of age. As the rats reached 60 and 70 days of age (Series $\mathrm{C}$ ) with mean body weights of 195 and $220 \mathrm{~g}$, FSH content rose sharply, finally reaching a mean of $744 \mu \mathrm{g} \mathrm{NIH-FSH-sl/gland.}$

These findings contrast with the findings in female rats of this colony. For the period after weaning, the graphs of pituitary FsH content in males and females are almost mirror-images. The final content reached by the males is higher than many values reported in the literature, but these values show considerable variation. Values of 610 and $640 \mu \mathrm{g}$ NIH-FSH-sl/gland have been found previously in adult males of a different colony (Brown, 1963).

We are grateful to the Population Council for a grant, to the Endocrine Study Section of the N.I.H. for supplies of purified Fsh, and to Mr A. C. Wyatt and Mrs Dianne Johnson for skilled assistance.

\section{REFERENCES}

Brown, P. S. (1963) Observations on a dithiocarbamoylhydrazine as an inhibitor of pituitary gonadotrophic activity. F. Endocr. 26, 425.

FAwke, L. \& Brown, P. S. (1970) Pituitary content of follicle-stimulating hormone in the female rat. 7. Reprod. Fert. 21, 303.

GOLDMAN, B. D. \& MAHESH, V. B. (1968) Fluctuations in pituitary FSH during the ovulatory cycle in the rat and a possible role of FsH in the induction of ovulation. Endocrinology, 83, 97.

Kragt, G. L. \& Ganong, W. F. (1968) Pituitary Fsh content in female rats at various ages. Endocrinology, 82, 1241 .

Steelman, S. L. \& Pohley, F. M. (1953) Assay of follicle stimulating hormone based on the augmentation with human chorionic gonadotropin. Endocrinology, 53, 604. 